\title{
STRUKTUR KOMUNITAS MANGROVE DI KELURAHAN TAPUANG, KECAMATAN TAHUNA, KABUPATEN SANGIHE
}

\author{
(Mangrove Community Structure in Tapuang Village, Tahuna Regency, \\ Sangihe District)
}

\section{Romario Pohos $^{1 *}$, Calvyn F. A. Sondak ${ }^{2}$, Antonius P. Rumengan², Deislie R.H. Kumampung $^{2}$, Veibe Warouw ${ }^{2}$, Ridwan Lasabuda ${ }^{3}$}

1. Mahasiswa Program Studi IImu Kelautan, FPIK, UNSRAT Manado

2. Staf Pengajar Program Studi IImu Kelautan, FPIK, UNSRAT Manado

3. Staf Pengajar Program Studi Manajemen Sumberdaya Perairan, FPIK, UNSRAT Manado

Penulis Korespondensi: Romario Pohos; Romario Pohos9@gmail.com

\begin{abstract}
Abstrak
Kawasan hutan mangrove yang ada dikelurahan Tapuang, sampai saat ini belum pernah dilaporkan tentang struktur komunitas mangrove. Keberadaan lokasi kawasan mangrove sangat dekat dengan pemukiman dan aktifitas manusia, terletak di bagian barat kelurahan Tapuang, Kecamatan Tahuna Timur, dan berada di bagian tenggara kelurahan Tidore. Pengambilan data dilakukan dengan metode line transek dimana terdapat satu stasiun dan tiga line transek, jarak antara line transek $50 \mathrm{~m}$.. Kemudian pada setiap line transek akan diletakan 5 kuadran yang berukuran $10 \mathrm{~m}$ x $10 \mathrm{~m}$. Berdasarkan dari hasil penelitan ditemukan 4 jenis mangrove yaitu Avicennia marina, Sonneratia alba, Sonneratia ovata, Rhizophora stylosa dan 1 tumbuhan asosiasi Nypa Fruticans. Avicennia marina merupakan sepesies yang paling dominan di setiap 3 transek dan memiliki nilai kerapatan, frekuensi, penutupan yang tertinggi Pada transek transek 2 nilai INP tertinggi yaitu jenis Avicennia marina dengan nilai 183,80. Keanekaragaman jenis mangrove di lokasi penelitian memiliki tingkat keanekaragaman yang rendah disetiap transek serta mengalami tekanan ekologi yang tinggi $\left(\mathrm{H}^{\prime} \leq 1\right)$ untuk tingkat pertumbuhan pohon kisaran indeks keanekaragaman (H') berkisar antara 0 - 0,99
\end{abstract}

Kata Kunci: Kelurahan Tapuang, Mangrove, Struktur komunitas

\begin{abstract}
The information about mangrove forest community structure in Tapuang village has never been reported. The location of the mangrove forest in this village is near to the settlements. Three line transects with $50 \mathrm{~m}$ distance were laid perpendicular to the shore. In each line transect, 5 quadrants $\left(10 \times 10 \mathrm{~m}^{2}\right)$ were established. The data were analyzed using several parameters density, frequency, dominance, important index value and diversity. This study found 5 mangrove species namely Avicennia marina, Sonneratia alba, Sonneratia ovata, Rhizophora stylosa and Nypa fruticans. Avicennia marina was the most species found in each transects and had the highest density, frequency, and dominance values. The highest important value index (INP) was found in Avicennia marina in transect 2 with a INP value 183.80. Mangrove species diversity index for tree category in each transect was low $\left(\mathrm{H}^{\prime} \leq 1\right)$ ranges from 0.99 .
\end{abstract}

Key Words: Tapuang Village, Mangrove, Community Structure 


\section{PENDAHULUAN}

Berdasarkan distribusi keaneka ragaman hayati dunia, Indonesia sering disebut kawasan mega-biodiversity, yaitu wilayah dengan keanekaragaman hayati tertinggi di dunia. Salah satu bagian dari keanekaragaman spesies yang dimiliki Indonesia yaitu hutan mangrove. Hutan mangrove merupakan ekosistem unik yang mendiami wilayah muara dan intertidal atau antar muka antara darat dan laut dikedua garis lintang tropis dan subtropis sebagian besar terbatas pada daerah antara $30^{\circ}$ Lintang Utara dan Lintang Selatan dari garis khatulistiwa (Das dkk., 2014).

Tumbuhan mangrove mampu beradaptasi dengan kondisi lingkungan yang ekstrim, seperti kadar garam yang tinggi, kondisi tanah yang kurang stabil serta kondisi tanah yang tergenang (Noor dkk., 2006). Struktur dan komposisi vegetasi setiap kawasan mangrove bervariasi tergantung pada kondisi tanah, pola curah hujan, dan masukan air sungai ke laut (Rahardi \& Suhardi, 2016).

Di Indonesia tercatat setidaknya ada 202 spesies mangrove yang terdiri atas 89 jenis pohon, 5 jenis palem, 19 jenis liana (pemanjat), 44 jenis epifit (herba tanah) dan 1 jenis sikas (paku) sehingga menjadikan hutan mangrove di Indonesia sebagai hutan mangrove yang memiliki keragaman jenis tertinggi di lingkungan Samudera Hindia dan Pasifik. Beberapa contoh mangrove yang dapat berupa pohon antara lain bakau (Rhizophora), api-api (Avicennia), pedada (Sonneratia), tanjang (Bruguiera), nyirih (Xylocarpus), tengar (Ceriops) (Noor dkk., 2006).

Sulawesi Utara memiliki hutan mangrove dengan luasan sekitar 28.000 hektar dengan 17 jenis mangrove dari 9 Famili dimana jenis yang dominan ditemukan adalah Rhizophora, Bruguiera dan Sonneratia (Karauwan, 2011). Berbagai peran mangrove bagi manusia sudah kian menjadi perhatian di Sulawesi Utara baik fungsinya sebagai penyerap karbon (Sondak, 2015; Rumengan dkk., 2018; Tiolong dkk., 2019) bahkan pemanfaatannya untuk silvofishery (budidaya ikan) (Rumengan dkk., 2019).

Melihat struktur komunitas dianggap penting dalam pelestarian ekosistem mangrove yang berkelanjutan, hal ini mendorong peneliti untuk melihat struktur komunitas mangrove di Kelurahan Tapuang, Kecamatan Tahuna Timur, Kabupaten Kepulauan Sangihe..

\section{METODE PENELITIAN}

Penelitian ini dilaksanakan di Kelurahan Tapuang, Kecamatan Tahuna Timur, Kabupaten Kepulauan Sangihe pada titik koordinat $3^{\circ} 36^{\circ} 03^{\prime \prime} \mathrm{N}$, $125^{\circ} 30^{`} 20^{\prime \prime} E$..

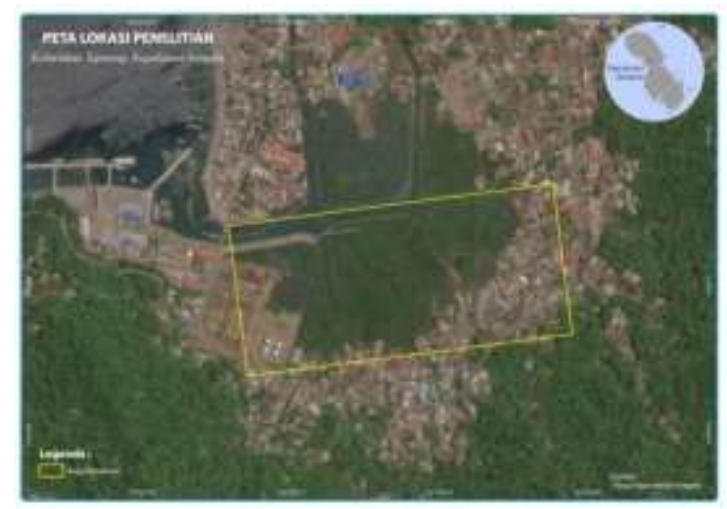

Gambar 1. Lokasi pengambilan data

Pengambilan data struktur
komunitas mangrove telah dilakukan
dengan metode line transek dimana
terdapat satu stasiun dan tiga line
transek, jarak antara line transek $50 \mathrm{~m}$.
Penarikan garis transek akan dilakukan
pada saat air surut dengan cara menarik
line transek sepanjang $100 \mathrm{~m}$ dari arah
laut ke darat. Pada setiap line transek
diletakan 5 kuadran $\left(10 \times 10 \mathrm{~m}^{2}\right)$.




\section{Analisis Data}

Analisis vegetasi merupakan cara untuk mengetahui struktur komunitas dalam suatu ekosistem mangrove untuk mencari Indeks Nilai Penting (INP) dan menentukan indeks keanekaragaman jenis dihitung dengan menggunakan rumus (Bengen, 2000)

Kerapatan Jenis

$$
\mathrm{Di}=\frac{\text { Jumlah total individu ke } 1}{\text { luar total area pengamatan }}
$$

\section{Kerapatan Relatif Jenis (RDi)}

$$
(\mathrm{RDi})=\frac{\text { Jumlah total individu ke } 1}{\text { total tegakan seluh jenis }}
$$

\section{Frekuensi Jenis (Fi)}

$$
(F i)=\frac{\text { jumlah petak ditemukan suatu jenis }}{\text { jumlah total petak yang dibuat }}
$$

\section{Frekuensi Relatif Jenis (RFi)}

$$
(\mathrm{RFi})=\frac{\text { jumlah } \text { jenis } k \text { e }-1}{\text { jumlah total petak } \text { yang dibuat }}
$$

\section{Penutupan Jenis (Ci)}

$$
(\mathrm{Ci})=\frac{\text { jumlah besar area } D B H \text { jenis } k e-1}{\text { luas total area petak } y \text { ang dibuat }}
$$

\section{Penutupan Relative Jenis (RCi)}

$$
(\mathrm{RCi})=\frac{\text { tutupan relatif jenis } k e-1}{\text { tutupan total untuk seluruh jenis }}
$$

Indeks Nilai Penting (INP)

$$
(I N P)=R D i+R F i+R C i
$$

Indeks Keragaman Jenis (H')

$$
H^{\prime}=-\sum_{i=1}^{s} \frac{n i}{N} \operatorname{In} \frac{n i}{N}
$$

Keterangan:

$H^{\prime}=$ Indeks keanekaragaman

$\mathrm{ni}=$ Jumlah individu masing-masing jenis

$$
\mathrm{N}=\text { Jumlah total individu semua jenis }
$$

\section{HASIL DAN PEBAHASAN}

\section{Jenis Jenis Mangrove}

Dari hasil penelitian yang dilakukan di kawasan mangrove yang terletak di Kelurahan Tapuang Kecamatan Tahuna Timur Kabupaten Kepulauan Sangihe ditemukan 5 jenis mangrove yaitu Avicennia marina, Sonneratia alba, Sonneratia ovata, Rhizophora stylosa dan Nypa fruticans.

\section{Kerapatan Jenis}

Berdasarkan hasil di lapangan nilai kerapatan jenis tertinggi disetiap transek terdapat pada jenis $A$. marina 0,07 ind $/ \mathrm{m}^{2}$ sedangkan nilai yang terendah $R$. stylosa $0,002 \mathrm{ind} / \mathrm{m}^{2}$ (Gambar 2). Tingginya nilai kerapatan $A$. marina diduga karena jumlah $A$. marina terbanyak ditemukan. Substrat lumpur merupakan media yang baik bagi vegetasi A.marina karena substrat lumpur memiliki hara dan nutrisi yang cukup bagi pertumbuhan dan perkembangan mangrove tersebut (Masruroh dan Insafitri, 2020). Vegetasi mangrove dapat tumbuh dengan baik pada substrat yang berlumpur dan dapat mentoleransi tanah lumpur berpasir (Bengen, 2004). Nilai kerapatan terendah jenis $R$. stylosa karena jenis ini dapat tumbuh pada habitat yang beragam di daerah pasang surut dengan, pasir dan batu (Noor dkk, 1999).

Sebagai perbandingan, Asman dkk,. (2020) menemukan nilai kerapatan 
tertingi hutan mangrove adalah 0,122 ind $/ \mathrm{m}^{2}, 0,25 \mathrm{ind} / \mathrm{m}^{2}$ (Jacobs dkk,. 2019), 0,05 ind $/ \mathrm{m}^{2}$ (Tidore dkk., 2021). Dari beberapa penelitian disimpulkan bahwa nilai kerapatan tinggi disebabkan oleh substrat yang cocok dan kemampuan beradptasi dengan lingkungan sekitarnya dan faktor yang menyebabkan pertumbuhan relatif jarang adalah kondisi akar yang besar sehingga pertumbuhan mangrove tersebut menjadi kurang optimal (Agustini dkk., 2016)

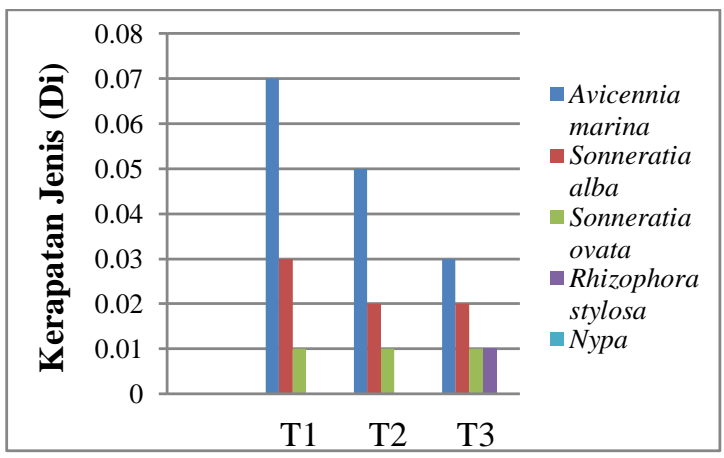

Gambar 2. Histogram Kerapatan Jenis di transek 1, 2 dan 3.

\section{Frekuensi Jenis}

Berdasarkan dengan hasil di lapangan nilai tertinggi frekuensi jenis terdapat pada jenis A.marina yaitu 1,00 jenis Nypa fruticans yaitu 0.2 (Gambar 3). Penelitian yang dilakukan oleh Asman dkk,. (2020) menemukan nilai frekuensi jenis tertingi yaitu 1, Jacobs dkk,. (2019) menemukan nilai frekuensi jenis tertinggi yaitu 1. Selain itu juga penelitian yg dilakukan oleh Tidore dkk., (2021) nilai frekuensi jenis tertinggi yaitu 1,00 Dari beberapa penelitian disimpulkan bahwa bahwa menurut Mangindaan dkk., (2012) nilai frekuensi mangrove dipengaruhi oleh banyaknya suatu jenis yang ditemukan pada setiap kuadran, makin banyak jumlah kuadran yang ditemukan jenis mangrove, maka nilai frekuensi kehadiran mangrove semakin tinggi

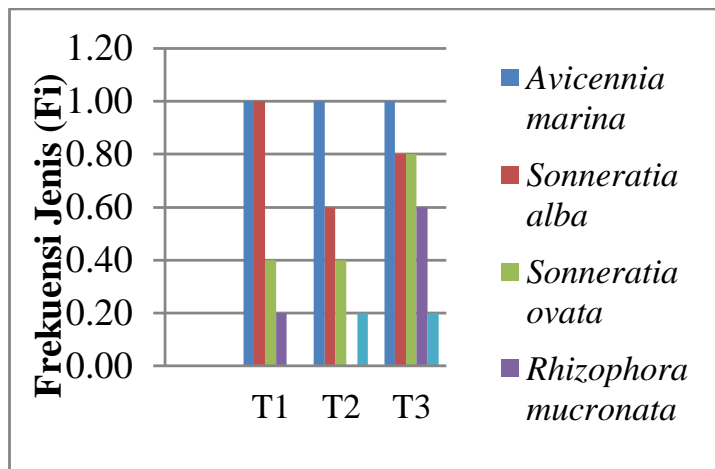

Gambar 3. Histogram Frekuensi Jenis di transek 1, 2 dan 3

\section{Penutupan Jenis}

Berdasarkan hasil dari lapangan nilai tertinggi penutupan jenis dimiliki oleh jenis A.marina dengan nilai 11,13 sedangkan nilai terendah jenis $R$. stylosa dengan nilai 0,03 (Gambar 4). Nilai penutupan jenis berhubungan erat dengan lingkar batang pohon. Ukuran lingkar batang pohon mangrove dari masing-masing jenis. Penutupan tertinggi pada jenis $A$. marina dari pada jenis yang lain hal ini berhubungan erat dengan diameter pohon, dimana jika diameter pohon berukuran besar maka akan memiliki nilai penutupan lebih besar (Gufran dan Kordi, 2012 dalam Akbar, dkk, 2015). Penelitian yang dilakukan oleh Asman dkk,. (2020) di Desa Lesah didapat nilai penutupan jenis tertingi yaitu $1,83 \mathrm{~m}^{2}, 207,87 \mathrm{~m}^{2}$ (Jacobs dkk. 2019). Selanjutnya Tidore dkk., (2021) nilai penutupan jenis tertinggi yaitu $16,16 \mathrm{~m}^{2}$. Mangrove yang berhadapan langsung dengan laut sehingga mendapatkan pasang surut air laut sangat mendukung jenis tersebut untuk tumbuh, kemudian yang mempangaruhi rendahnya nilai penutupan jenis karena mangrove yang heterogen (Sofian dkk., 2012). 


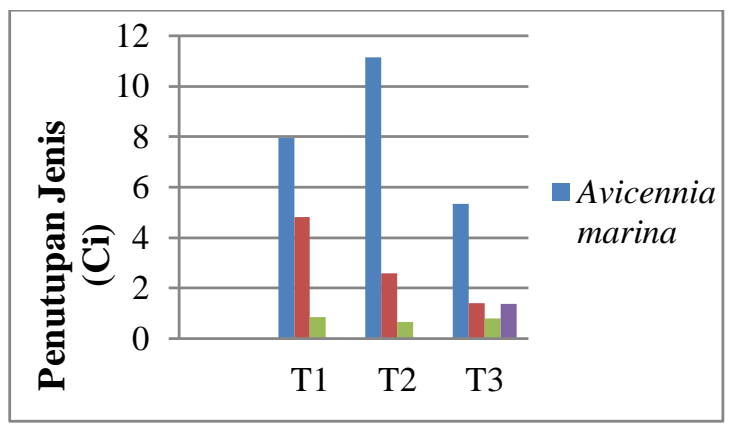

Gambar 4. Histogram Penutupan Jenis di transek 1, 2 dan 3.

\section{Indeks Nilai Penting}

Indeks nilai penting (INP) tertinggi ditemukan pada $A$. marina dengan nilai 183,80 dan nilai terkecil yaitu jenis mangrove asosiasi $N$. fruticans dengan nilai 8,59 (Gambar 5). Hal ini menunjukan bahwa jenis $A$. marina memiliki peran yang cukup penting bagi ekosistem mangrove di lokasi penelitian. Penelitian yang dilakukan oleh Asman dkk., (2020) menemukan INP tertinggi 182,12\% kemudian Tidore dkk, ( 2021) 136,26 Jacobs dkk.. (2019) 100,59), 136,57 (Gabi dkk, 2021), 179,75 (Takarendehang dkk. 2018).

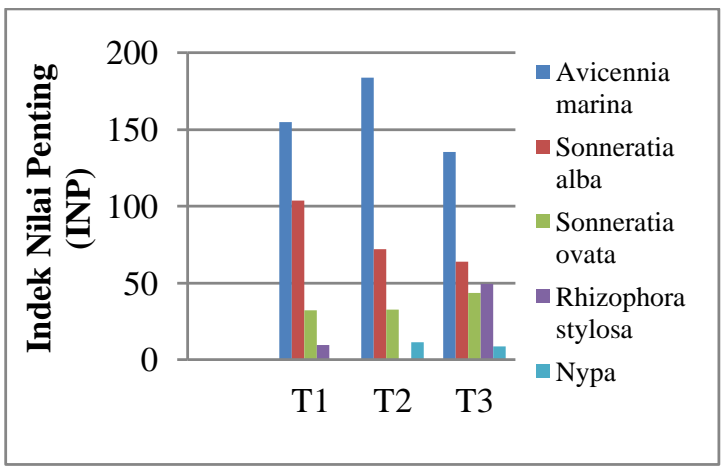

Gambar 5. Indeks Nilai Penting di transek 1, 2 dan 3

\section{Indeks Keanekaragaman}

Indeks keanekaragaman adalah ukuran kekayaan komunitas dilihat dari jumlah spesies dalam suatu kawasan beserta jumlah individu dari setiap spesies (Kontu, 2014 dalam Babo dkk., 2020). Nilai indeks keanekaragaman tertinggi yaitu 0,99 dan yang terendah 0,3 (Gambar 6). Keanekaragaman jenis mangrove di lokasi penelitian berdasarkan indeks memiliki tingkat keanekaragaman yang rendah disetiap transek ini menunjukan bahwa pertumbuhan mangrove tidak stabil mungkin karena ada jenis yg mati dan juga disebabkan oleh faktor kimia memiliki tingkat keanekaragaman yang rendah disetiap transek serta mengalami tekanan ekologi yang tinggi $\left(H^{\prime} \leq 1\right)$ untuk tingkat pertumbuhan pohon kisaran indeks keanekaragaman ( $\left.\mathrm{H}^{\prime}\right)$ berkisar antara 0 - 0,99.

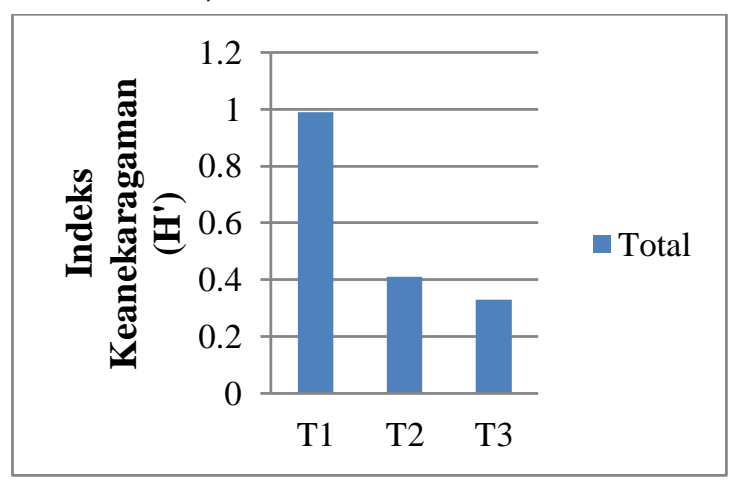

Gambar 6. Indeks Keanekaragaman di transek 1, 2 dan 3

\section{KESIMPULAN}

Berdasarkan dari hasil penelitan terhadap struktur komunitas mangrove di kelurahan Tapuang Kecamatan Tahuna Barat, Kab Kepulauan Sangihe maka dapat disimpulkan bahwa ditemukan 5 jenis mangrove yaitu Avicennia marina, Sonneratia alba, Sonneratia ovata, Rhizophora stylosa dan Nypa fruticans. Nilai INP tertinggi dimiliki Avicennia marina dengan nilai 183,80 dan nilai terkecil yaitu jenis Nypa fruticans dengan nilai 8,59. Keanekaragaman jenis mangrove di lokasi penelitian memiliki 
tingkat keanekaragaman yang rendah disetiap transek serta mengalami tekanan ekologi yang tinggi $\left(H^{\prime} \leq 1\right)$ untuk tingkat pertumbuhan pohon kisaran indeks keanekaragaman $\left(\mathrm{H}^{\prime}\right)$ berkisar antara 0 0,99

\section{DAFTAR PUSTAKA}

Amin, D. N., Irawan, H., \& Zulfikar, A. (2015). Hubungan jenis substrat dengan kerapatan vegetasi rhizophora sp. di hutan mangrove Sungai Nyirih Kecamatan Tanjung Pinang Kota Tanjung Pinang. Repository UMRAH, 1(1), 1-15.

Asman, I., Sondak, C.F.A., Schaduw, J.N.W., Kumampung, D.R.H., Ompi, M., Sambali, H. 2020. Struktur Komunitas Mangrove Di Desa Lesah, Kecamatan Tagulandang, Kabupaten Sitaro. Jurnal Pesisir Dan Laut Tropis, 8(2): 48-60.

Babo, P. P., Sondak, C. F. A., Paulus, J. J. H., Schaduw, J. N., Angmalisang, P. A., \& Wantasen, A. S. (2020). Struktur Komunitas Mangrove Di Desa Bone Baru, Kecamatan Banggai Utara, Kabupaten Banggai Laut, Sulawesi Tengah. Jurnal Pesisir Dan Laut Tropis, 8(2), 92. https://doi.org/10.35800/jplt.8.2.20 20.29951

Bengen, D.G. 2000. Pedoman Teknis Pengenalan dan Pengelolaan Ekosistem Mangrove, Pusat Kajian Sumberdaya Pesisir dan Lautan. IPB. Bogor..

Bengen, D.G. 2004. Sinopsis Ekosistem dan Sumberdaya Pesisir dan Laut Serta Prinsip Pengelolaannya. Cetakan Ketiga. Bogor: Pusat Kajian SumberDaya Pesisir dan Lautan, Institut Pertanian Bogor.
Das, S. K., D. Samantaray, H. Thatoi. $2014 . \quad$ Ethnomedicinal, antimicrobial and antidiarrhoeal studies on the mangrove plants of the genus Xylocarpus: A mini review, J Bioanal Biomed., S12:004, hal. 1-7.

Gabi, F.G., Sondak, C.F.A., Kumampung, D.R.H., Darwisito, S., Ompi, M., Rembet, U.N.W.J. 2021. Struktur Komunitas Mangrove di Desa Gamlamo, Kecamatan Jailolo, Halmahera Barat, Provinsi Maluku Utara. Jurnal Pesisir Dan Laut Tropis: 9(3): 34-43

Jacobs, R., Kusen, J.D., Sondak, C.F.A., Boneka, F.B., Warouw, V., Mingkid, W.M. 2019. Struktur Komunitas Mangrove dan Kepiting Bakau di Desa Lamanggo dan Desa Tope, Kecamatan Biaro, Kabupaten Kepulauan Siau, Tagulandang dan Biaro. Jurnal Pesisir Dan Laut Tropis: 1(1):2028

Karauwan, M. 2011. Kondisi Ekosistem Mangrove Di Kecamatan Bunaken Sulawesi Utara.Jurnal. Ekowisata Edisi II.

Masruroh, L., \& Insafitri, I. (2020). PENGARUH JENIS SUBSTRAT TERHADAP KERAPATAN VEGETASI Avicennia marina DI KABUPATEN GRESIK. Juvenil:Jurnal IImiah Kelautan Dan Perikanan, 1(2), 151-159. https://doi.org/10.21107/juvenil.v1i 2.7569

Rahardi, W. dan R.M. Suhardi.2016. Keanekaragaman Hayati dan Jasa Ekosistem Mangrove di Indonesia.Prosiding Symbion (Symposium on Biology Education), Prodi Pendidikan 
Biologi, FKIP, Universitas Ahmad Dahlan, hal.499-510.

Rahim, S., \& Baderan, D. W. K. (2019). Komposisi jenis, struktur komunitas, dan keanekaragaman mangrove asosiasi Langge Kabupaten Gorontalo Utaraprovinsi Gorontalo. Jurnal IImu Lingkungan, 7(1), 181-188.

Rumengan, A.P., D.C.A. Lintong, E.S. Mandiangan, H.J. Sinjal., C.P. Paruntu. 2019. Penerapan Teknologi Budidaya Ikan (Silvofishery) di Kawasan Hutan Mangrove bagi Masyarakat Pesisir Bolaang Mongondow Selatan.Jurnal IImiah Tatengkorang, Volume 3, hal.4551.

Rumengan, A.P., D.M.H. Mantiri, R. Rompas, A. Hutahaean, T.L. Kepel, C.P. Paruntu, R.C. Kepel, G.S. Gerung. 2018. Carbon stock assessment of mangrove ecosystem in Totok Bay, southeast Minahasa Regency, North Sulawesi, Indonesia. AACL Bioflux, 11(4): hal. 1280-1288.

SNI 7724:2011. 2011. Pengukuran dan penghitungan cadangan karbon Pengukuran lapangan untuk penaksiran cadangan karbon hutan (ground based forest carbon accounting). BSN: Jakarta.

Sondak, C.F.A. 2015. Estimasi Potensi Penyerapan Karbon Biru (Blue Carbon) Oleh Hutan Mangrove Sulawesi Utara. Universitas Sam Ratulangi, Manado. Jurnal of Asean Studies on Maritime Issues. Vol. 2 (1): 45-52.
Takarendehang, R., Sondak, C.F.A., Kaligis, E.Y., Kumampung, D.R.H., Manembu, I.S., Rembet, U.N.W.J. Kondisi Ekologi dan Nilai Manfaat Hutan Mangrove di Desa Lansa, Kecamatan Wori, Kabupaten Minahasa Utara. Jurnal Pesisir Dan Laut Tropis: 1(1):20-28

Tambunan, I., M.T. Yunasfi, Desrita. 2017.Keanekaragaman Mangrove Dan Kelimpahan Makrozoobentos di Desa Bagan Asahan Kecamatan Tanjung Balai Kabupaten Asahan Provinsi Sumatera Utara. Program Studi Manajemen Sumberdaya Perairan. Fakultas Pertanian. Universita Sumatera Utara. 12 hal.

Tidore S, Sondak, C.F.A., Rumengan, A.P., Kaligis, E.Y., Ginting, E.L. Kondoy, C. 2021. Struktur komunitas mangrove di Desa Budo, Kecamatan Wori, Kabupaten Minahasa Utara. Jurnal Pesisir dan Laut Tropis, 9(2): hal. 71-78

Tiolong, G.M., A.P. Rumengan, C.F.A. Sondak, F.B. Boneka, N.G.F. Mamangkey, C. Kondoy. 2019. Estimasi Karbon Vegetasi Mangrove di Kelurahan Pintu Kota Kecamatan Lembeh Utara Kota Bitung. Jurnal Pesisir dan Laut Tropis, 7(2): hal. 98-103. 